\title{
FIXAÇÃO DE CARBONO EM SISTEMAS AGROECOLÓGICOS NA REGIÃO DO VALE DO SÃO PATRÍCIO, GOIÁS
}

\section{CARBON SEQUESTRATION IN AGROECOLOGICAL SYSTEMS IN THE REGION OF THE SÃO PATRÍCIO VALLEY, GOIÁS}

\author{
José Aparecido de Andrade Júnior ${ }^{1}$, Blayder Ribeiro de Souza ${ }^{1}$, Rodrigo Fernandes Souza ${ }^{2}$, Jadson \\ Belem de Moura ${ }^{2}$
}

\begin{abstract}
${ }^{1}$ Graduado em Agronomia - Faculdade Evangélica de Goianésia jaa.jr@outlook.com
${ }^{2}$ Professor do Curso de Agronomia - Faculdade Evangélica de Goianésia - rodrigo.souza@evangelicagoianesia.edu.br
\end{abstract}

\begin{abstract}
Resumo: O objetivo deste trabalho foi quantificar a massa verde de cobertura, massa seca de serapilheira e o carbono do solo em cinco sistemas agroecológicos, Sistema Agrosilvopastoril, Sistema Agroflorestal, Programa Agroecológico Integrado e Sustentável, Isolamento de Nascente, e Isolamento de Mata Ciliar, em três idades de implantação. O delineamento experimental utilizado foi inteiramente casualizados com os tratamentos dispostos em um fatorial de $5 \times 3$ com três repetições, onde um fator é composto pelos sistemas de cultivo. Nos valores de fixação de carbono em biomassa verde fresca superficial sem considerar a idade de implantação dos sistemas, o tratamento SASP foi superior aos tratamentos SAF, PAIS, isolamento de nascente e mata ciliar; Nos valores de carbono fixado em massa seca de serapilheira, desconsiderando a idade de implantação do sistema, os tratamentos isolamento de Nascente e Mata ciliar apresentaram valores estatisticamente superiores que os tratamentos SASP, SAF e PAIS; Nos valores de massa verde de cobertura, considerando a idade de implantação dos sistemas, os tratamentos recém implantados apresentaram valores estatisticamente inferiores que as áreas com 2 anos de e 4 anos de implantação; Não houve diferença mínima significativa ao analisar os valores de massa seca de serapilheira em diferentes épocas de implantação dos sistemas; Levando em consideração a idade de implantação verificou-se que os sistemas agroecológicos implantados há dois anos se destacaram em relação aos demais; Quanto à fixação de carbono no solo desconsiderando a idade de implantação, os sistemas de isolamento de nascentes e de mata ciliares foram superiores aos demais; Ao analisar o comportamento dos estoques de carbono de biomassa verde de cobertura no SAF, não foi identificado diferença estatística entre as idades de implantação do sistema; Não houveram diferenças estatística para os valores de massa Verde e massa seca nas diferentes épocas de implantação no PAIS; Nos valores de fixação de carbono no solo no PAIS, o sistema com idade de implantação de dois anos foi superior ao sistema recém implantado, que por suavez, foi superior ao sistema com idade de implantação de 4 anos; Ao avaliar o comportamento dos estoques de carbono com o passar do tempo no tratamento Isolamento de Nascentes, os valores de Massa Verde sofreram incremento com o passar do tempo, onde as áreas com 4 anos de implantação apresentaram valores estatisticamente superiores que os demais tratamentos; Não foi observado diferença mínima significativa estatística ao se investigar os valores de carbono fixados em isolamento de matas ciliares

Palavras-chave: Agroecologia, SASP, Agrofloresta, PAIS, Isolamento de Nascente.
\end{abstract}

Abstract: The objective of this study was to quantify the carbon fixed in green mass coverage, dry mass of litter and soil carbon in five agroecological systems, System Agrosilvopastoril, Agroforestry System, Integrated Agroecology and Sustainable Programme, Spring insulation, and insulation of Riparian Forest in three deployment ages. The experimental design was completely randomized with the treatments in a $5 \times 3$ factorial design with three replications, where one factor is composed of cropping systems. In carbon sequestration values in surface fresh green biomass of different ecological systems of production without considering the age of deployment of the systems, the SASP treatment was superior to SAF treatments, PAIS, insulation spring and riparian vegetation; In carbon values set in dry mass of litter, disregarding the age of system implementation, the insulating East and Riparian vegetation 
treatments were statistically superior values that the SASP treatments, SAF and PAIS; In the green mass values coverage, considering the age of deployment of the systems, the newly deployed treatments showed statistically lower values that areas with 2 years and 4 years of implementation; There was no significant minimum difference by analyzing the dry mass of litter values in different systems deployment times; Taking into account the age of deployment of agroecological systems, it turns out that the agroecological systems deployed two years ago stood out compared to the other; Fixing carbon in the soil disregarding the age of deployment, the insulation systems of springs and riparian forest were superior to others; By analyzing the behavior of carbon stocks of green biomass coverage in SAF, it was not identified statistical difference between the system deployment ages; There were no statistical differences for the green mass and dry weight values in different deployment times in PAIS; In carbon sequestration in the soil values in PAIS, the system aged deployment two years was higher than the newly implemented system, which in turn was higher than the system aged deployment of 4 years; In assessing the behavior of carbon stocks over time in the treatment Isolation springs, the Green Massa suffered values increase over time, where areas with 4 years of implantation showed statistically higher values than the other treatments; There was no statistically significant minimum difference to investigate carbon values established in isolation of riparian forests

Keywords: Agroecological, SASP, Agroforestry, PAIS, Spring insulation.

\section{INTRODUÇÃO}

Nos últimos anos, muito tem se falado sobre aquecimento global, efeito estufa e outros fenômenos causados ou potencializados pela ação das atividades humanas (TOLENTINO et al., 2014).

Esse fenômeno ocorre de forma natural e é de fundamental importância para a existência de vida no planeta (YU, 2004). Segundo Carvalho et al., (2010), o efeito estufa natural ocorre devido às concentrações de Gases de Efeito Estufa (GEE) na atmosfera antes mesmo do aparecimento do homem. Estes gases são responsáveis por reter parcialmente a energia solar na atmosfera aumentando a temperatura média do ar. E sem esses gases, que atuam como um cobertor natural ao redor da terra, a radiação infravermelha térmica solar absorvida se dissiparia no espaço e a superfície do nosso planeta seria $33^{\circ} \mathrm{C}$ mais fria do que é hoje (YU, 2004).

O problema é o aumento da concentração dos GEE na atmosfera, devido às atividades humanas como a queima de combustíveis fósseis e o desmatamento, isso tem causado preocupação, pois essas ações podem alterar as condições básicas para a vida no planeta (FERNANDES et al., 2007).

Os gases responsáveis pelo efeito são: Dióxido de carbono, Metano, Óxido nitroso, Hexafluoreto de enxofre, Ozônio, Clorofluorcarbonetos (CFCs), Hidroclorofluorcarbonetos (HCFCs) (TOLENTINO et al., 2014).

Entre os GEE, o gás carbônico (CO2) é o principal responsável pela intensificação do efeito-estufa e, 
resultando em mudanças climáticas. Dentre essas mudanças, verifica-se que a temperatura média do planeta está cada vez mais elevada. E apresenta de forma cada vez mais frequente instabilidades no regime pluviométrico em diversas regiões do planeta, incluindo o Brasil (FERNANDES et al., 2007).

O cerrado é o segundo maior bioma brasileiro (depois da Amazônia) e concentra nada menos que um terço $\mathrm{da}$ biodiversidade nacional e $5 \%$ da flora e da fauna mundiais. Os cerrados brasileiros correspondem a mais de 200 milhões de hectares distribuídos nas regiões centro-oeste, norte, nordeste e sudeste, e possui grandes riquezas naturais renováveis adaptadas as rígidas condições climáticas, edáficas, e hídricas (RATTER et al., $1997)$.

Com o aumento da exploração das terras do cerrado, as técnicas de manejo visando à conservação dos recursos naturais presente neste bioma se tornam indispensáveis (RESCK et al., 2008), segundo Lopes (1983), a matéria orgânica do solo é fundamental para manutenção da fertilidade do solo dos cerrados.

Segundo $\mathrm{Yu}$ (2004), os quatro principais estoques de carbono são a atmosfera, os oceanos, os depósitos de combustível fóssil e a biomassa terrestre e solo e o sequestro de carbono é proporcional ao crescimento da planta. Sendo assim, quanto maior o seu porte, mais biomassa se acumula, e consequentemente mais carbono é fixado. A maior parte do carbono terrestre está acumulada no solo florestal pela decomposição de matéria orgânica.

O desmatamento e a implantação de agrossistemas tendem a reduzir o teor de carbono (C) no solo, principalmente devido à erosão, e redução da produção de massa verde (CARVALHO et al., 2010).

No sistema convencional de preparo de solo é realizada a remoção da vegetação nativa deixando o solo exposto ao impacto direto de forças erosivas, o que provoca a desagregação das partículas (WOHLENBERG et al., 2004). Esse tipo de preparo devido a ruptura dos agregados, acarretará a perda de matéria orgânica (C), em especial na faixa de até $20 \mathrm{~cm}$ de profundidade (CASTRO FILHO et at., $1998)$.

Os sistemas agroecológicos se resumem na aplicação de conceitos e princípios da Ecologia, da Agronomia, da Sociologia, da Antropologia, da ciência da Comunicação, da Economia Ecológica e de outras áreas em novos métodos de manejo, que objetiva a sustentabilidade com o tempo, e a substituição dos modelos 
convencionais por modelos sustentáveis (CAPORAL et al., 2002). Dentre O S sistemas agroecológicos destacam-se:

$$
\text { SASP - Sistema Agro Silvo }
$$

Pastoril: Consiste na introdução de árvores na pastagem, com o objetivo de aumentar a quantidade e disponibilidade de nutrientes das culturas consorciadas por meio da interceptação dos nutrientes localizados em camadas mais profundas do solo pelas raízes das árvores, e disponibilizando-os na superfície para as forrageiras. Isso ocorre com a deposição e decomposição de seu material vegetativo (GYENGE et al., 2002).

$$
\text { PAIS - Produção Agroecológica }
$$

Integrada e Sustentável (Sistema Mandala): O PAIS, consiste em um reservatório de água para criação de peixes ou uma estrutura para manejo de pequenos animais sendo circulado por canteiros com o intuito de aproveitar melhor o espaço, tendo em vista que o sistema é utilizado na maioria das vezes em pequenas propriedades. Normalmente neste sistema é cultivado hortaliças e olerícolas em geral (MESSIANO et al., $2008)$.

SAF - Sistema Agro Florestal: Consiste no cultivo de espécies frutíferas, nativas e exóticas, de médio a grande porte, onde se espera uma maior produção de material vegetativo, e consequentemente uma maior ciclagem de nutrientes por meio da decomposição da serapilheira (ARATO et al., 2003).

Isolamento de Nascentes e Matas Ciliares (APP's) Consiste no isolamento da área a ser recuperada, com o objetivo de impedir o acesso de animais às áreas protegidas, e permitir sua recuperação de forma natural (ZANZARINI et al., 2004).

O objetivo deste trabalho foi quantificar a massa verde de cobertura, massa seca de serapilheira e o carbono do solo em cinco sistemas agroecológicos, Sistema Agro-SilvoPastoril (SASP), Sistema Agroflorestal (SAF), Produção Agroecológica Integrada e Sustentável (PAIS), Isolamento de Nascente, e Isolamento de Mata Ciliar, em três idades de implantação, em três assentamentos da região do Vale do São Patrício/GO.

\section{MATERIAL E MÉTODOS}

As amostragens foram realizadas em março de 2015 nos sistemas agroecológicos em parcelas dos assentamentos Vitória (15²7'40.1"S 49०04'35.2"W), Presente de Deus

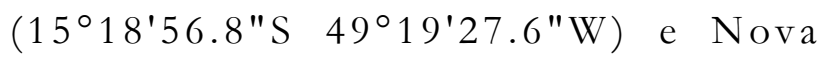
Aurora $\left(15^{\circ} 19^{\prime} 09.3^{\prime \prime S} \quad 49^{\circ} 23^{\prime} 17.7^{\prime \prime W}\right)$ (Figura 1). O delineamento experimental utilizado foi inteiramente casualizado com os 
tratamentos dispostos em um fatorial de $5 \times 3$ com três repetições, em que o primeiro fator é composto pelos sistemas de cultivo: Sistema AgroSilvo-Pastoril ( SASP), Sistema Agroflorestal $(\mathrm{SAF})$,
Programa
Agroecológico Integrado e Sustentável (PAIS), Isolamento de Nascente, e Isolamento de Mata Ciliar; e o segundo fator é por três épocas: Sistema em implantação, 2 anos em atividade e 4 anos em atividade.

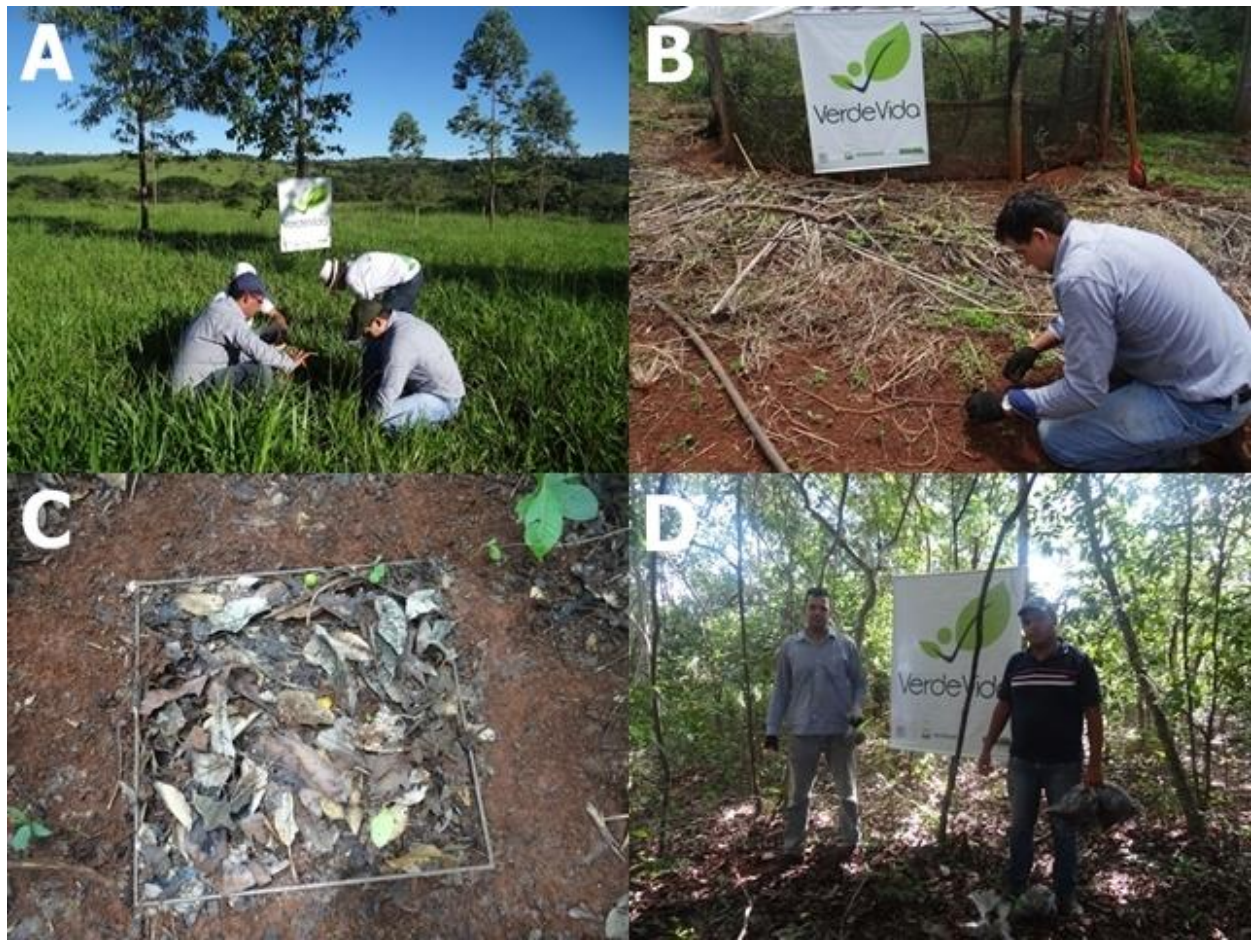

Figura 1. A mostragens em campo. A - SASP assentamento Presente de Deus, B - PAIS assentamento Presente de Deus, C - Nascente assentamento Nova Aurora, D - Mata Ciliar assentamento Vitória.

Em cada um dos tratamentos foram coletadas três amostras compostas, de biomassa seca de serapilheira, biomassa verde de cobertura e solo para determinação de carbono do solo.

Para coleta da serapilheira foi utilizado um aro nas dimensões $1 \mathrm{mx} 1 \mathrm{~m}$. As amostras foram armazenadas em sacos de papel devidamente identificados. Para a coleta do solo foi utilizada cavadeira, e retirado uma porção do solo na profundidade de $0-20 \mathrm{~cm}$.

As análises laboratoriais foram realizadas no laboratório de fitotecnia da Faculdade Evangélica de Goianésia. Para determinação de carbono de biomassa verde e biomassa de serapilheira, as amostras de biomassa foram secas em estufa de ventilação forçada à $65^{\circ} \mathrm{C}$, e pesadas diariamente até a estabilização do peso de acordo com o método proposto por (MIYAZAWA et al., 2000). O carbono de solo foi determinado de acordo com o método proposto por (MIYAZAWA et al., 2000), onde $50 \mathrm{~g}$ amostras de solo foram submetidas à temperatura de $105^{\circ}$ por 24 horas em estufa, com o objetivo de eliminar a umidade, feito isso o material foi pesado e submetido à temperatura de $400^{\circ} \mathrm{C}$ por 4 horas para eliminação do carbono orgânico, a quantificação de carbono presente nas amostras se deu por meio da diferença entre os pesos inicial e final das amostras.

Os dados obtidos foram submetidos à análise de variância utilizando-se o software estatístico Assistat 7.7 Beta e as médias 
comparadas pelo teste de Scott-Knott a $5 \%$ de probabilidade.

\section{RESULTADOS E DISCUSSÃO}

Houve diferença mínima significativa entre as variáveis sistemas, idade e interação para os parâmetros massa verde e carbono do solo. O parâmetro massa seca apresentou diferença mínima significativa somente nos sistemas avaliados e entre a interação entre sistema e idade (Tabela 1 ).

Tabela 1. Teste de médias e diferentes sistemas de cultivo com diferentes épocas de implantação.

\begin{tabular}{lccc}
\hline & & Teste F & \\
\cline { 2 - 4 } Fonte de Variação & Massa Verde & Massa Seca & Carbono do Solo \\
\hline Sistema (F1) & $5.9704^{*}$ & $10.4822^{*}$ & $2.8498^{*}$ \\
Idade (F2) & $4.0241^{*}$ & $1.9704 \mathrm{~ns}$ & $34.4917^{*}$ \\
Interação (F1xF2) & $5.6112^{*}$ & $3.7056^{*}$ & $3.3378^{*}$ \\
\hline
\end{tabular}

*: significativo ao nível de $5 \%$ de probabilidade $(.01=<\mathrm{p}<.05)$

Ns: não significativo $(\mathrm{p}>=.05)$

Ao avaliar a biomassa verde fresca superficial de diferentes sistemas ecológicos de produção sem considerar a idade de implantação dos sistemas, o tratamento SASP foi superior aos tratamentos SAF, PAIS, isolamento de nascente e mata ciliar (Figura 2).

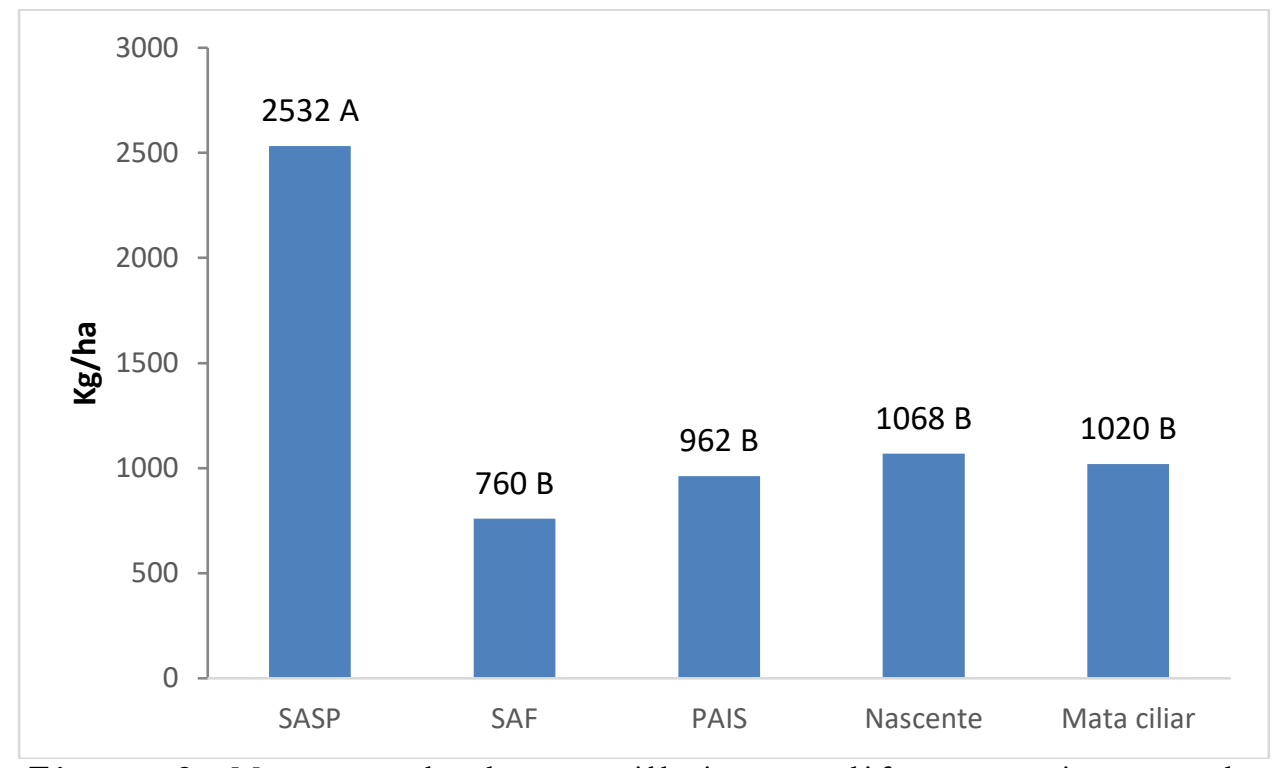

Figura 2. Massa verde de serapilheira em diferentes sistemas de cultivo no cerrado.

Este comportamento pode ser explicado pelo acúmulo de biomassa que normalmente ocorre em agrosistemas de pastagens (XAVIER et al., 2011), é sistemática a adoção de espécies que grande volume de biomassa fresca, como as espécies gramíneas (PACIULLO et al., 2003).

Os tratamentos SAF, PAIS, Isolamento de nascente e mata ciliar não possuem como manejo o cultivo de pastagens. Por este motivo, nestas condições experimentais, os valores de carbono em biomassa viva são inferiores que o tratamento SASP (PEREIRA et al., 2012).

Entretanto, ao se avaliar a massa seca de serapilheira desconsiderando a idade de implantação do sistema, os tratamentos isolamento de Nascente e Mata ciliar apresentaram valores estatisticamente superiores que os tratamentos SASP, SAF e PAIS (Figura $3)$. 


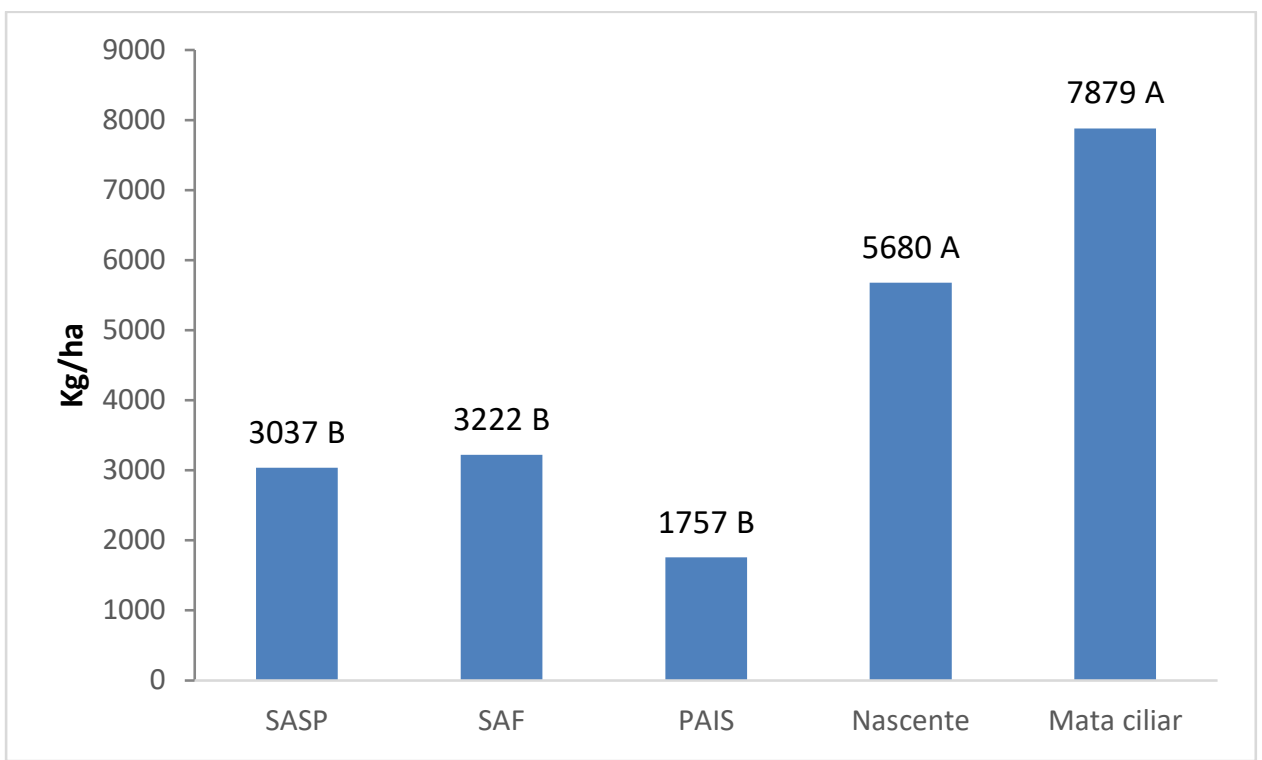

Figura 3. Massa seca de serapilheira em diferentes sistemas de cultivo no cerrado.

Áreas de várzea e com maiores teores de umidade tem sua decomposição de matéria orgânica diminuída, pois os organismos mais eficientes na decomposição são os aeróbicos. Em ambientes saturados de agua a decomposição é feita em sua maioria por organismos anaeróbicos, e estes não são tão eficientes. Motivo pelo qual o acumulo de matéria orgânica em organossolos acontece em áreas de várzea (NEUE et al., 1997)

Outro motivo é que os microclimas dessas regiões, geralmente, são mais amenos, o que também diminui a velocidade de decomposição, pois a atividade microbiana é diretamente proporcional ao aumento de temperatura, diminuindo, assim, o aporte de serapilheira (BERTOL et al., 2004).

Ao avaliar a massa verde de cobertura, considerando a idade de implantação dos sistemas, houve diferença mínima significativa entre os tratamentos. O tratamento onde os sistemas foram recém implantados apresentaram valores estatisticamente inferiores que as áreas com 2 anos de e 4 anos de implantação (Figura 4).

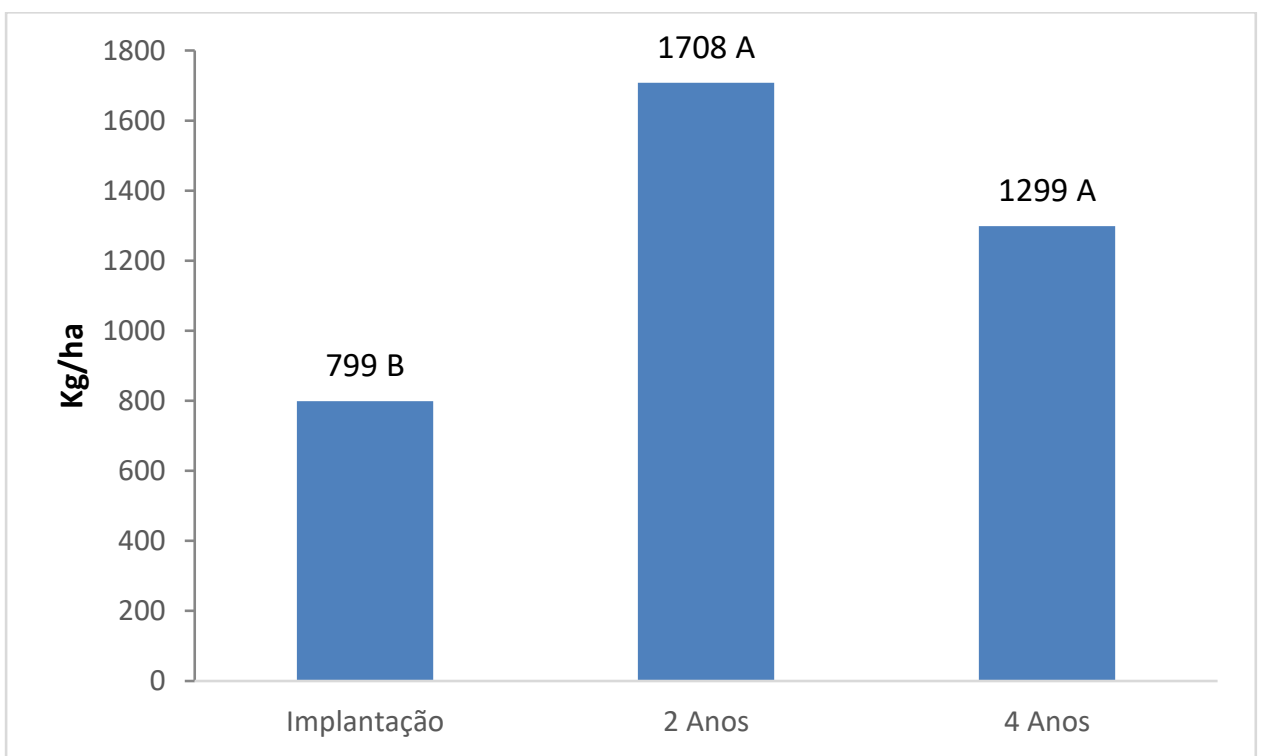

Figura 4. Massa verde de serapilheira em épocas de amostragem no cerrado. 
O aumento de carbono fixado durante o tempo se dá devido à ausência de práticas de manejo tidas como convencionais como gradação, queima e monocultivo (CARVALHO et al., 2010).

Práticas agroecológicas tem como premissa a manutenção dos recursos naturais e a sustentabilidade dos meios de produção, logo o aumento no aporte de carbono com o passar do tempo é um comportamento esperado (CAPORAL et al., 2002).

Entretanto não houve diferença mínima significativa ao analisar os valores de massa seca de serapilheira em diferentes épocas de implantação dos sistemas (Figura 5).

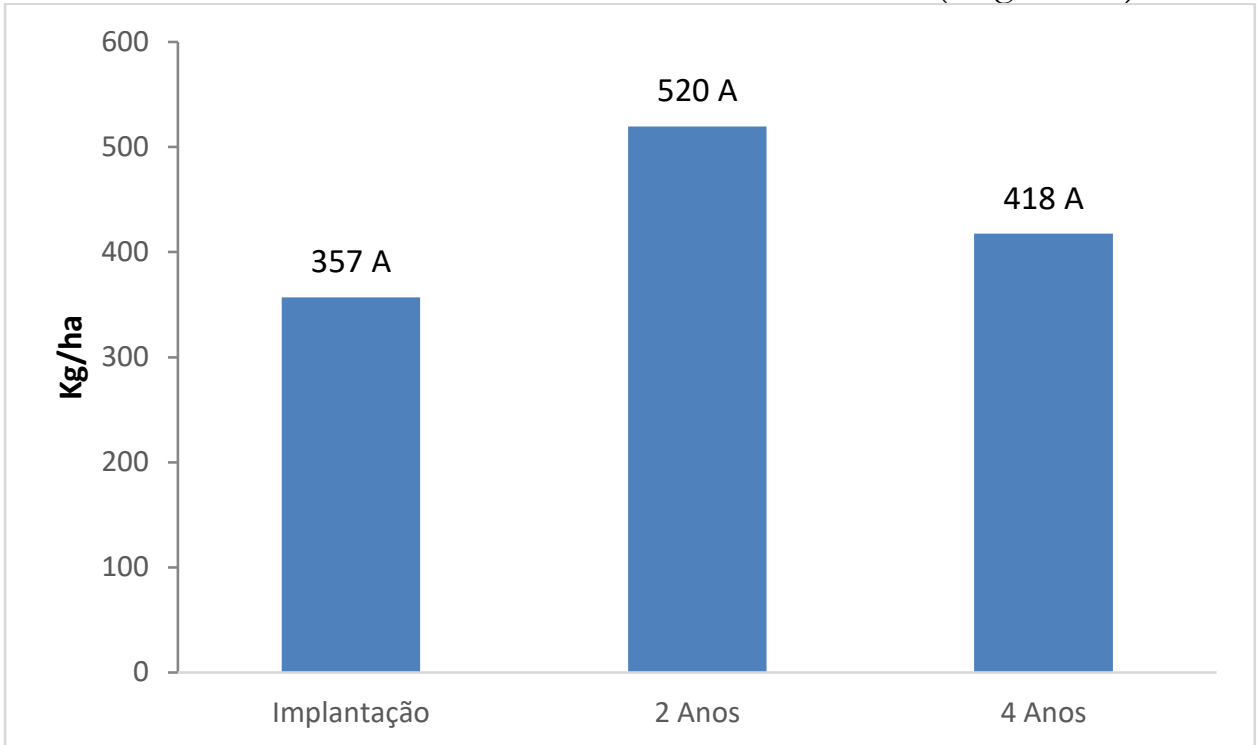

Figura 5. Massa seca de serapilheira em épocas de amostragem no cerrado.

A manutenção dos níveis de carbono fixado em matéria seca carbono fixado em massa seca de serapilheira se dá pelo mesmo motivo que houve um maior de carbono em massa fresca com o passar do tempo. Sistemas agroecológicos evitam a queima dos estoques de matéria estáveis (CARVALHO et al., 2010).

Levando em consideração a idade de implantação dos sistemas agroecológicos, verifica-se que os sistemas agroecológicos implantados orgânica, mantendo os níveis de

há dois anos se destacaram em relação de aos demais (Figura 6).

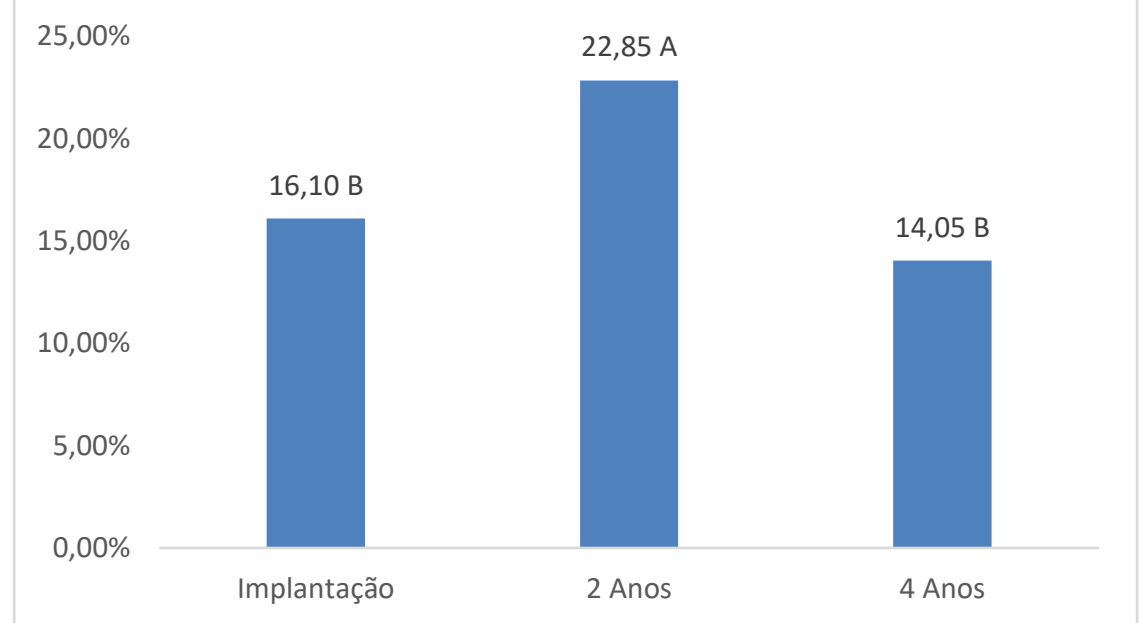

Figura 6. Carbono no solo em diferentes épocas de implantação no cerrado.

Quanto à fixação de carbono no solo desconsiderando a idade de implantação, os sistemas de isolamento de nascentes e de mata 
ciliares foram superiores aos demais (Figura 7).

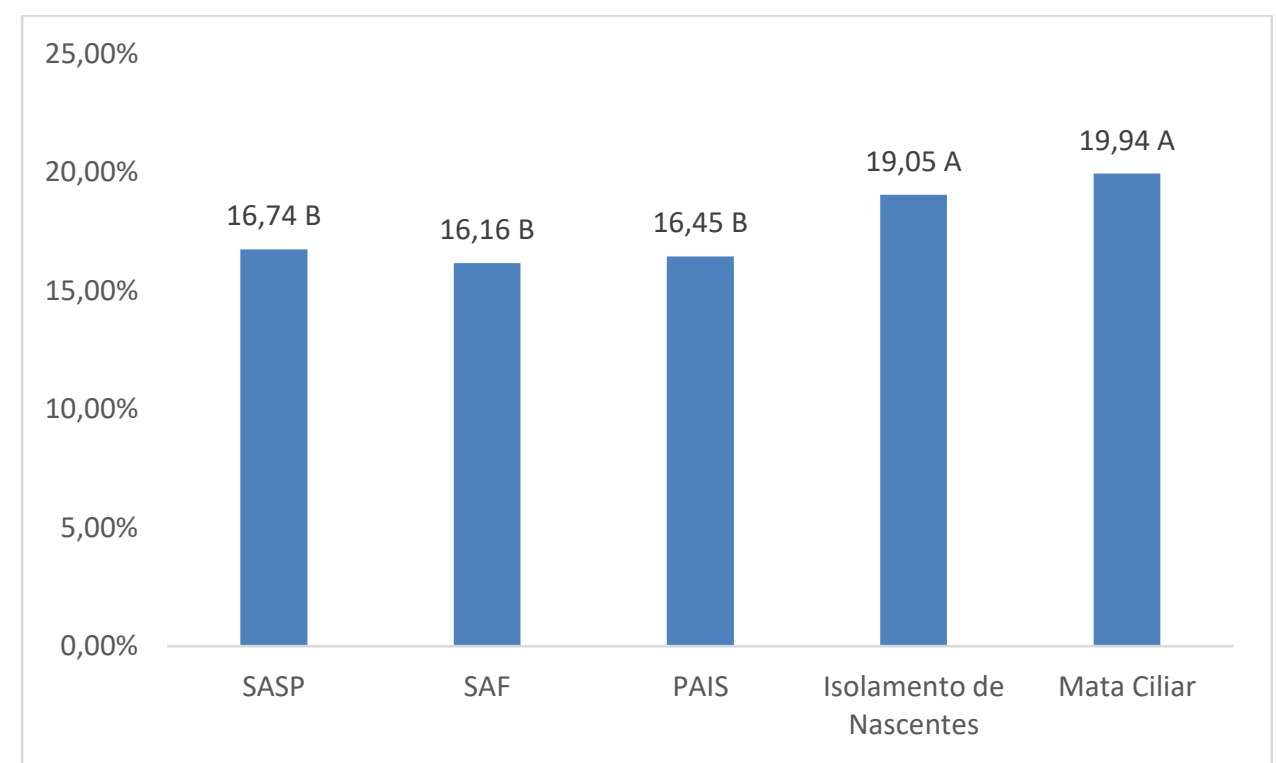

Figura 7. Carbono no solo (\%) em diferentes sistemas de cultivo no cerrado.

Ao avaliar o estoque de carbono no SASP, os valores de Massa Verde foram superiores no segundo ano de implantação, quando comparado aos demais.

Os sistemas com idade de implantação de dois e quatro anos foram superiores ao sistema recémimplantado considerando os valores de Massa Seca.

O comportamento dos valores de carbono do solo foi semelhante ao comportamento de biomassa seca de serapilheira.

Áreas com má drenagem tem sua atividade microbiana diminuída, estes organismos que atuam como decompositores primários são prejudicados em ambientes com baixo teor de oxigênio, por isso estas áreas têm maiores aportes de carbono fixado em solo e em cobertura morta (NEUE et al., 1997).

O clima em regiões com presença de corpos hídricos é mais ameno, colaborando para diminuição da atividade dos microrganismos decompositores de matéria orgânica (BERTOL et al., 2004).

$$
\text { Houve diferença mínima }
$$
significativa ao se avaliar o comportamento dos estoques de carbono no sistema Agrossilvipastoril com o passar do tempo (Figura 8)

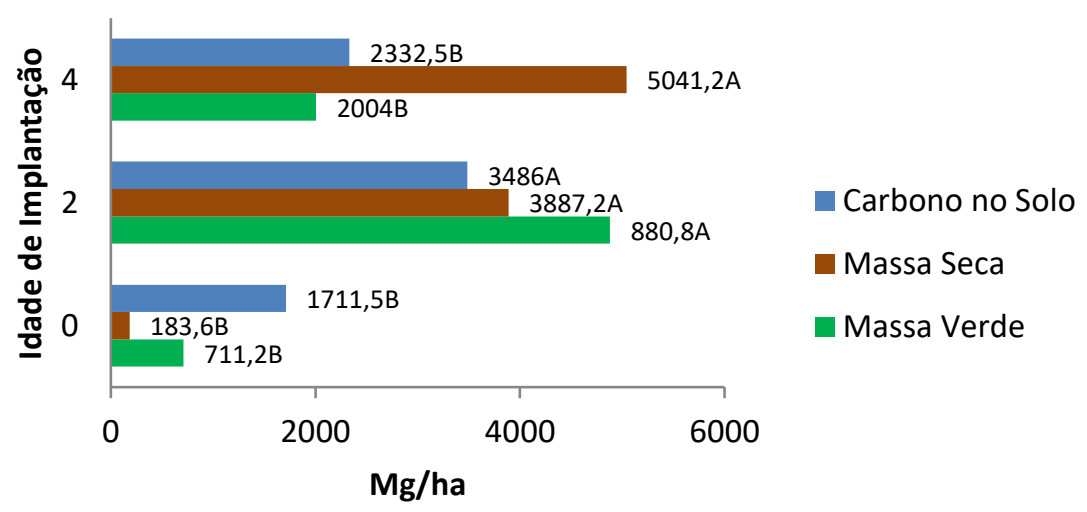

Figura 8. Massa Verde, Massa Seca e Carbono no Solo, em diferentes épocas de implantação no Sistema Agrosilvipastoril. 
Como visto nas figuras 3,4 e 5 , houve incremento nos sistemas de cultivo com o passar do tempo.

O carbono fixado em massa verde de cobertura e em carbono do solo sofreram incremento com o passar do tempo, sendo a época de dois anos de implantação, superior às demais épocas.

O carbono dos estoques de massa seca de serapilheira, também apresentaram diferenças significativas, onde as épocas de 2 e 4 anos apresentaram valores maiores de estoque de carbono quando comparado ao sistema recém implantado.

Segundo Bernadino et al., (2009) e Almeida (2010) o sistema silvipastoril assegura maior sustentabilidade aos ecossistemas se comparado aos sistemas de monocultivo. E as árvores aumentam a deposição de serapilheira nas pastagens, e que pode contribuir para a sustentabilidade da pastagem (XAVIER et al., 2011)

Os valores relativamente inferiores de estoque de carbono de massa verde e carbono no solo no sistema com idade de quatro anos de implantação em relação aos sistemas recém implantados e com dois anos, não representa necessariamente o comportamento dos tratamentos. Somente é possível determinar o comportamento de aporte de carbono ao se realizar estudos em uma mesma área em diferentes épocas. Rosendo (2012), afirma que pastagem má formada, manejo inadequado e/ou a superlotação levam à sua degradação e compromete o sequestro de carbono pelo sistema.

Ao analisar o comportamento da biomassa verde de cobertura no SAF, não foi identificada diferença estatística entre as idades de implantação do sistema (Figura 9).

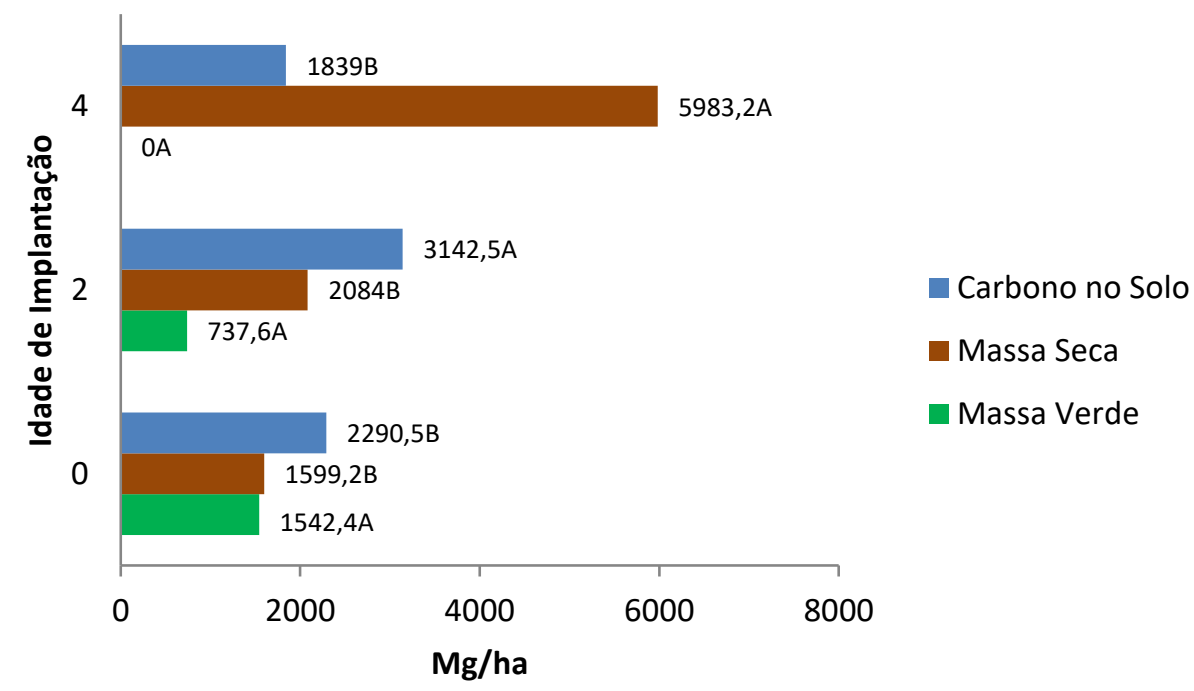

Figura 9. Massa Verde, Massa Seca e Carbono no Solo, em diferentes idades de implantação do Sistema AgroFlorestal.

A Massa Seca de serapilheira no SAF sofreram incremento com o passar do tempo, onde no sistema implantado há quatro anos foi superior aos demais. O valor de carbono no solo fixado no sistema com idade de implantação de dois anos foi superior aos demais.
Segundo Bolfe et al., (2009), o Sistema Agroflorestal possui grande capacidade de acumular C na biomassa. Os sitemas agroflorestais tendem a acumular carbono ao longo do tempo, podendo possibilitar a recuperação de 
áreas que sofreram com ações antropicas (RODRIGUES et al., 2000)

A quantidade e época de deposição das folhas, pode variar de acordo com a espécie e condições climáticas da região. Segundo Fávero (2008), os sistemas agroflorestais por propiciarem uma melhor dinâmica do carbono no solo por meio da deposição de sedimentos das árvores, este sistema tem potencial de recuperar áreas degradadas, quando bem manejados.

O valor relativamente inferior quanto a concentração de carbono no solo, no sistema com idade de implantação de quatro anos não representa o comportamento real do carbono no sistema avaliado. As áreas analisadas, por serem agroecosistemas cultivados com diferentes manejos impossibilita o levantamento do real comportamento dos estoques de carbono. Para isso é necessário o estudo em uma mesma área com o passar do tempo.

Não houveram diferenças estatística para os valores de massa Verde e massa seca nas diferentes épocas de implantação no PAIS. Já quanto a fixação de carbono no solo, o sistema com idade de implantação de dois anos foi superior ao sistema recém implantado, que por sua vez, foi superior ao sistema com idade de implantação de 4 anos (Figura 10).

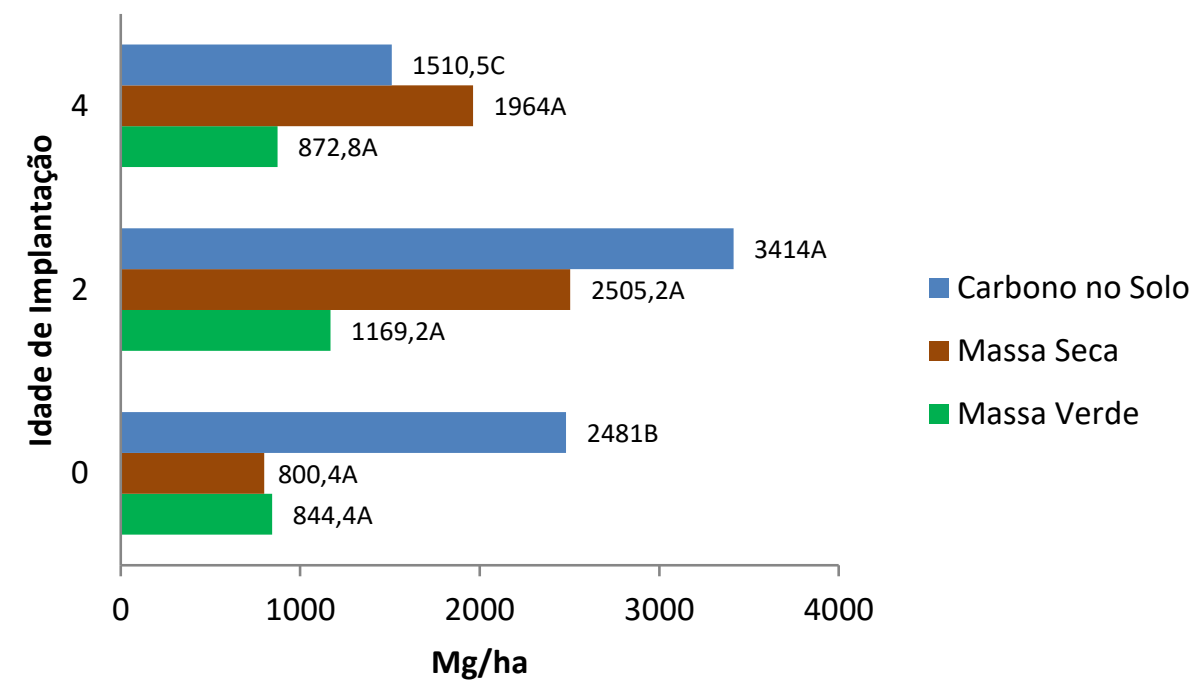

Figura 10. Massa Verde, Massa Seca e Carbono no Solo, em diferentes idades de implantação do programa Agroecológico Integrado Sustentável.

Para Lourente et al., (2008), as praticas agrícolas de forma geral reduzem a matéria orgânica do solo, e a diversidade de espécies nos cultivos podem favorecer a conservação do solo e o sistema PAIS tem como premissa a manutenção da biodiversidade vegetal entre as espécies cultivadas.
Ao avaliar o comportamento dos estoques de carbono com o passar do tempo no tratamento Isolamento de Nascentes, os valores de Massa Verde sofreram incremento com o passar do tempo, onde as áreas com 4 anos de implantação apresentaram valores estatisticamente superiores que os demais tratamentos (Figura 11). 


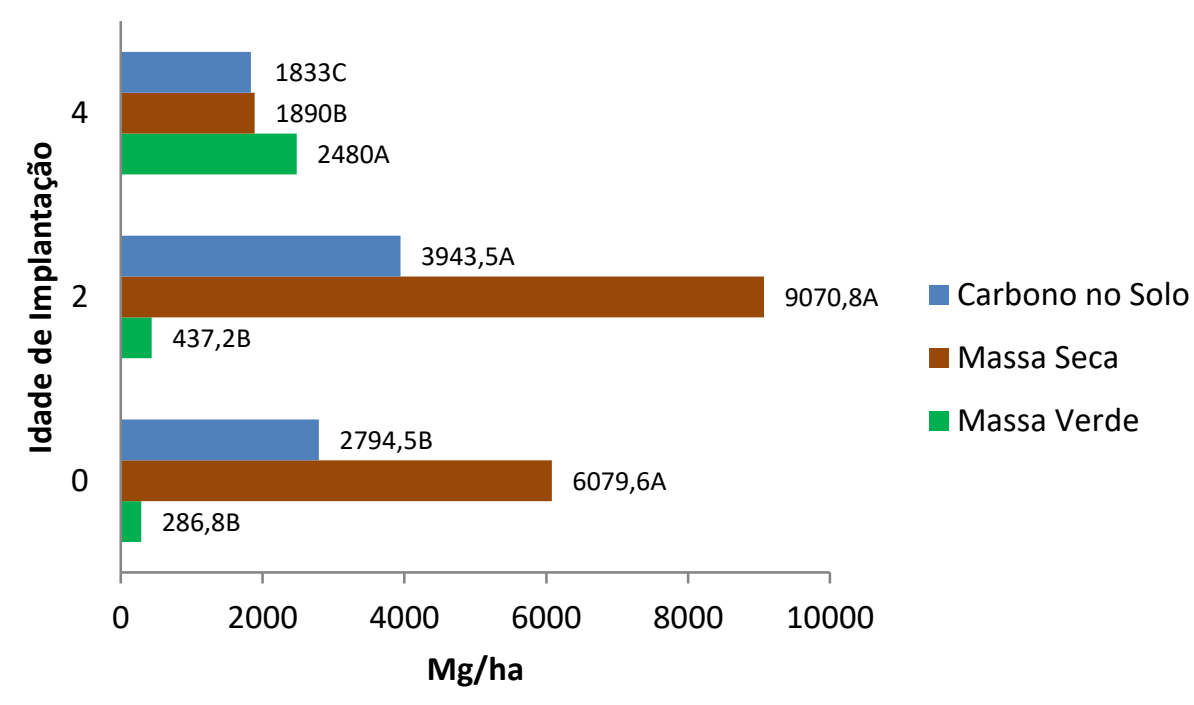

Figura 11. Massa Verde, Massa Seca e Carbono no Solo, em diferentes idades de implantação de Isolamento de Nascentes.

Em relação à Massa Seca, os sistemas recém implantados e com idade de implantação de dois anos, foram superiores ao sistema com quatro anos. Já quanto a fixação de carbono no solo, o sistema com idade de implantação de dois anos foi superior ao sistema recém implantado, que por sua vez, foi superior ao sistema com idade de implantação de 4 anos. Essa diminuição no acumulo de carbono fixado em massa seca de serapilheira pode ser explicado pela diminuição da morte da parte viva de cobertura vegetal (FERNANDES et at,. 2015)
Segundo Alvarenga et al., (2006) a condução da regeneração natural é importante para obtenção de bons resultados. Os valores relativamente inferiores quanto deposição de massa seca, e a concentração de carbono no solo, no sistema com idade de implantação de quatro anos, em relação aos demais tratamentos não necessariamente representa que esses valores decaíram ao longo do tempo.

Não foi observado diferença mínima significativa estatística ao se investigar os valores de carbono fixados em isolamento de matas ciliares (Figura 12).

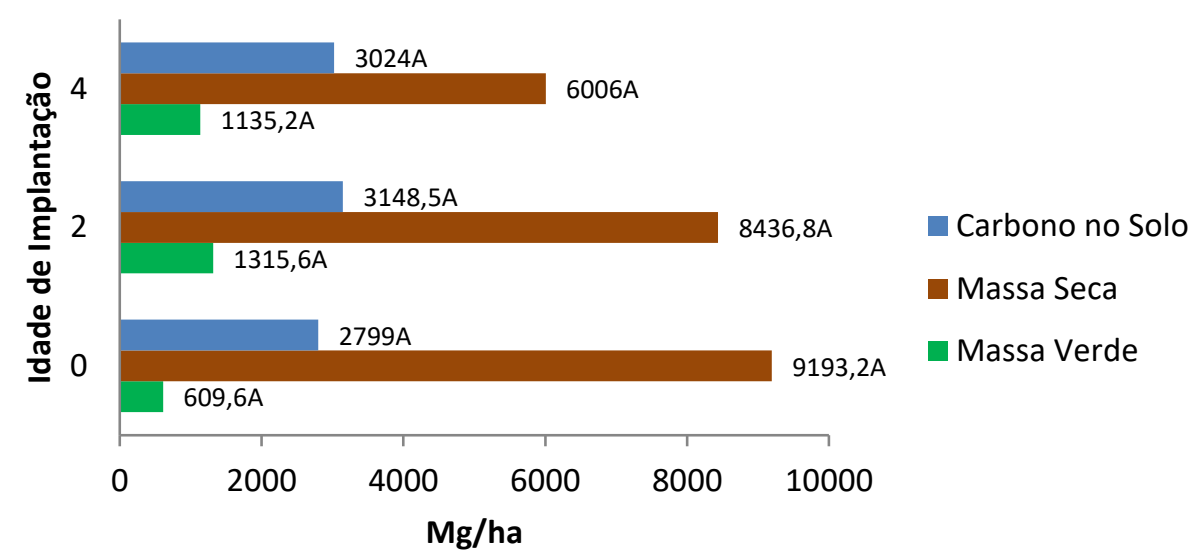

Figura 12. Concentrações e Massa Verde, Massa Seca e Carbono no Solo, em diferente idade de implantação de Isolamento de Mata Ciliar. 
A manutenção dos estoques de carbono é um bom sinal, indica que o sistema evita a queima dos estoques de carbono e emissão em forma de gazes causadores do efeito estufa.

\section{CONCLUSÕES}

Nos valores de fixação de carbono em biomassa verde fresca superficial de diferentes sistemas ecológicos de produção sem considerar a idade de implantação dos sistemas, o tratamento SASP foi superior aos tratamentos SAF, PAIS, isolamento de nascente e mata ciliar;

Nos valores de carbono fixado em massa seca de serapilheira, desconsiderando a idade de implantação do sistema, os tratamentos isolamento de Nascente e Mata ciliar apresentaram valores estatisticamente superiores que os tratamentos SASP, SAF e PAIS;

Nos valores de massa verde de cobertura, considerando a idade de implantação dos sistemas, os tratamentos recém implantados apresentaram valores estatisticamente inferiores que as áreas com 2 anos de e 4 anos de implantação;

Não houve diferença mínima significativa ao analisar os valores de massa seca de serapilheira em diferentes épocas de implantação dos sistemas;

Levando em consideração a idade de implantação dos sistemas agroecológicos, verifica-se que os sistemas agroecológicos implantados há dois anos se destacaram em relação aos demais;

Quanto à fixação de carbono no solo desconsiderando a idade de implantação, os sistemas de isolamento de nascentes e de mata ciliares foram superiores aos demais;

Ao analisar o comportamento dos estoques de carbono de biomassa verde de cobertura no SAF, não foi identificado diferença estatística entre as idades de implantação do sistema;

Não houveram diferenças estatística para os valores de massa
Verde e massa seca nas diferentes épocas de implantação no PAIS;

Nos valores de fixação de carbono no solo no PAIS, o sistema com idade de implantação de dois anos foi superior ao sistema recém implantado, que por sua vez, foi superior ao sistema com idade de implantação de 4 anos;

Ao avaliar o comportamento dos estoques de carbono com o passar do tempo no tratamento Isolamento de Nascentes, os valores de Massa Verde sofreram incremento com o passar do tempo, onde as áreas com 4 anos de implantação apresentaram valores estatisticamente superiores que os demais tratamentos;

Não foi observado diferença mínima significativa estatística ao se investigar os valores de carbono fixados em isolamento de matas ciliares

\section{REFERÊNCIAS}

ALMEIDA, R. G. Sistemas agrossilvipastoris: benefícios técnicos, econômicos, ambientais e sociais. ENCONTRO SOBRE ZOOTECNIA DE MATO GROSSO DO SUL, v. 7, p. 1-10, 2010.

ALVARENGA, A.P.; BOTELHO, S.A.; PEREIRA, I.M. Avaliação da regeneração natural na recomposição de matas ciliares em nascentes na região sul de Minas Gerais. Cerne, Lavras, v. 12, n. 4, p. 360-372, 2006.

BERTOL, I.; LEITE, D.; ZOLDAN JR, W. A. Decomposição do resíduo de milho e variáveis relacionadas. Revista Brasileira de Ciência do Solo, v. 28, n. 2, p. 369 375, 2004.

BOLFE, E. L.; FERREIRA, M. C.; BATISTELLA, M. Biomassa epígea e estoque de carbono de agroflorestas em Tomé-Açu, PA.Cadernos de Agroecologia, v. 4, n. 1, 2009. 
CAPORAL, F. R.; COSTABEBER, J. A. Agroecologia: enfoque científico e estratégico. Agroecologia e desenvolvimento rural sustentável, Porto Alegre, v. 3, n. 2, p. 13-16, 2002.

CARVALHO, J. L. N.; AVANZI, J. C.; SILVA, M. L. N.; MELLO, C. R. D.; CERRI, C. E. P. Potencial de sequestro de carbono em diferentes biomas do Brasil. Revista Brasileira de Ciência do Solo, 2010.

FÁVERO, C; LOVO, I. C.; MENDONÇA, E. de S. Recuperação de área degradada com sistema agroflorestal no Vale do Rio Doce, Minas Gerais. Revista Árvore, v. 32, n. 5, p. 861-868, 2008 .

FERNANDES, M.; MATRICARDI, E. A. T. Aporte e Decomposição da Serapilheira na Caatinga no Sul do Piauí. Floresta e Ambiente, v. 22, n. 1, p. 42-49, 2015.

LOURENTE, E. R. P.; MERCANTE, F. M.; TOKURA, A. M.; MIOTTO, D.; COLAÇO, F. W.; VIANA, C. M. Atributos químicos e microbiológicos avaliados em sistemas de cultivos agrícolas e florestais. Revista Brasileira de Agroecologia, v. 3, n. 2, 2009.

MIYAZAWA, M.; PAVAN, M.A.; OLIVEIRA, E.L.; IONASHIRO, M.; SILVA, A.K. Gravimetric Determination of Soil Organic Matter. Brazilian Archives of Biology and Technology, 43:475478,2000 .

NEUE, H. U.; GAUNT, J. L.; WANG, Z. P. Carbon in tropical wetlands. Geoderma, v. 79, n. 1, p. 163-185, 1997.
PACIULLO, D. S. C.; AROEIRA, L. J. M.; AlviM, M. J.; CARVALhO, M. M. Características produtivas e qualitativas de pastagem de braquiária em monocultivo e consorciada com estilosantes. Pesquisa Agropecuária Brasileira, v. 38, n. 3, p. 421-426, 2003.

PEDRO, LO de A. Carbono do solo e a mitigação da mudança climática global. Quim. Nova, v. 28, n. 2, p. 329-334, 2005.

PEREIRA， F. C.; UYEDA, C. A.; LIMA, A. D. O.; GUEDES, V.; COSTA, L. L.; ROCHA, C. S. Recuperação De Nascentes Com Sabiá (Mimosa caesalpiniifolia, BENTH) FABACEAE NO AGRESTE PARAIBANO.

RODRIGUES, V. G. S.; CASTILLA, C.; COSTA, R. S. C. D.; PALM, C. Estoque de carbono em sistema agroflorestal com café RondôniaBrasil. 2000 .

ROSENDO, J. S.; ROSA, R. Comparação Do Estoque De C Estimado Em Pastagens E Vegetação Nativa De Cerrado. Sociedade \& Natureza, v. 24, n. 2, p. 359-375, 2012.

XAVIER, D. F.; DA SILVA LÉDO, F. J.; DE CAMPOS PACIULLO, D. S.; PIRES, M. D. F. Á.; BODDEY, R. M. Dinâmica da serapilheira em pastagens de braquiária em sistema silvipastoril monocultura. Pesquisa

Agropecuária Brasileira, v. 46, n. 10, p. 1214-1219, 2011.

YU, C. M. Sequestro florestal de carbono no Brasil: dimensões políticas, socioeconômicas e ecológicas. Annablume, 2004. 